anchored to the air/solution interface. From this result is easily inferred a folding of the alkanediyl chain and its penetration into the inner micelle. The folding can also be examined by the following approach. The partial molar volume $v$ of tetradecanesulfonate anion in the micellar state is estimated to be $254.4 \mathrm{~cm}^{3}$ $\mathrm{mol}^{-120}$ by applying the Stokes' radius of $1.84 \AA$ to the sodium ion. Then, the micellar surface area $(S)$ made only of surfactant ions is given by

$$
S=(4 \pi)^{1 / 3}(3 \bar{n} v)^{2 / 3}
$$

where the micelles are assumed to be spherical due to relatively small aggregation numbers. On the other hand, the distance $(d)$ between anionic head groups is related with the above surface area in the form

$$
S=(\sqrt{3} / 2) \bar{n} d^{2}
$$

where the hexagonal packing is assumed as for the anionic groups.

(20) Tanaka, M.; Kaneshina, S.; Sin-no, K.; Okajima, T.; Tomida, T. J. Colloid Interface Sci. 1974, 46, 132.
From the $v$ and $\bar{n}$ values obtained above, the distance $d$ can be evaluated for each counterion. At the same time, the distance between two cationic charges in the counterions is also evaluated from the CPK model. These two distances are plotted against the carbon number of the alkanediyl group of the counterions (Figure 6). From this figure, the distance between the two cationic charges of the counterions becomes longer than that between anionic head groups of micellized surfactant ions above an eight $\mathrm{CH}_{2}$ groups separation of counterions, which also strongly indicates the folding of the alkanediyl chain of the counterions.

The above two simplified calculations substantiate the assumption made from the cmc change in the previous paper ${ }^{12}$ that the divalent cationic charges whose separation is more than eight methylene groups become anchored to the micellar surface due to electrostatic attraction by anionic head groups of surfactant ions, while the alkanediyl chain folds and penetrates into a hydrophobic inner micelle, leading to a decrease in cmc.

Registry No. $\mathrm{C}_{2} \mathrm{BP}, 46347-63-1 ; \mathrm{C}_{4} \mathrm{BP}, 33884-65-0 ; \mathrm{C}_{6} \mathrm{BP}, 80038$ $42-2 ; \mathrm{C}_{8} \mathrm{BP}, 80038-44-4 ; \mathrm{C}_{10} \mathrm{BP}, 47244-14-4 ; \mathrm{C}_{12} \mathrm{BP}, 47377-62-8 ; \mathrm{C}_{14} \mathrm{BP}$, 47510-98-5.

\title{
Reduction and Cluster Growth of Palladlum in Zeolite Y Containing Transition Metal Ions. X-ray Absorption Studies
}

\author{
Karin Moller and Thomas Bein* \\ Department of Chemistry, University of New Mexico, Albuquerque, New Mexico 87131 \\ (Received: April 28, 1989; In Final Form: July 13, 1989)
}

\begin{abstract}
The effect of a second transition metal on the reducibility and agglomeration behavior of palladium in zeolite $\mathrm{Y}$ is studied by EXAFS spectroscopy. Special attention is given to the potential bonding interactions between both metal constituents that could result in "chemical anchoring" of the noble metal to the support via the unreduced cocation. Zeolite $Y$ was coexchanged with $\mathrm{Fe}^{2+}$ or $\mathrm{Co}^{3+}$ and $\mathrm{Pd}^{2+}$ and with each ion alone. Dehydration in oxygen atmosphere and reduction with hydrogen was performed at different temperatures up to $623 \mathrm{~K}$. The structure of the samples during various stages of pretreatment and reduction was studied with EXAFS on both absorption edges. Palladium is partially reduced to $\mathrm{Pd}^{0}$ at room temperature and forms small metal clusters at higher temperatures. Iron is oxydized under oxygen atmosphere and is partially present in the form of iron oxide particles, which are redispersed under reducing conditions. A small enhancement of the reducibility of palladium is observed if iron is present in the zeolite, but neither a chemical anchoring nor an effect on the final agglomeration process of palladium is detected by the presence of iron cations. In contrast, coexchange with cobalt results in a substantially higher dispersion of the $\mathrm{Pd}(0)$ phase after high-temperature reduction. Apparently, the change in cation distribution induced by the Co ions influences the reduction process of palladium. When palladium ions are diffused into the zeolite containing aqueous $\mathrm{Fe}(\mathrm{II})$ ions, a $\mathrm{Pd}(0)$ phase consisting of larger crystallites is formed at room temperature by a redox reaction with $\mathrm{Fe}(\mathrm{II})$.
\end{abstract}

\section{Introduction}

The preparation of supported small metal particles continues to attract wide interest due to its importance in catalytic applications. Numerous studies have shown the sometimes dramatic effect of a second metal on the catalytic behavior of a metal catalyst. $^{1-7}$ Structural studies on the formation of metal/support catalyst systems under different conditions are a prerequisite for

(1) Sinfelt, J. H. Bimetallic Catalysts-Discoveries, Concepts and Application; Wiley: New York, 1983.

(2) Moroz, B. L.: Semikolenov, V. A.; Likholobov, V. A.; Yermakov, Y. I. J. Chem Soc., Chem. Commun. 1982, 1286.

(3) Rao, L.-F.; Fukuoka, A.; Ichikawa, M. J. Chem Soc., Chem. Commun. $1988,458$.

(4) Fukuoka, A.; Kimura, T.; Ichikawa, M. J. Chem Soc., Chem. Commun. 1988, 428

(5) Choudary, B. M.; Lazar, K.; Matusek, K.; Guczi, L. J. Chem Soc., Chem. Commun. 1988, 592

(6) Tebassi, L.; Sayari, A.; Ghorbel, A.; Dufaux, M.; Naccache, C. J. Mol. Catal. 1984, 397.

(7) Augustine, S. M.; Sachtler, W. M. H. J. Phys. Chem. 1987, 9I, 5953 their rational design. X-ray diffraction (XRD) and transmission electron microscopy (TEM) allow determination of the presence of different phases and particle sizes but have limited utility when amorphous metals and/or clusters of dimensions smaller than 20 $\AA$ are present. In this context, extended X-ray absorption spectroscopy (EXAFS) is complementary to $\mathrm{X}$-ray diffraction studies since it is most sensitive for the local structure in a range smaller than about $5 \AA$ around the absorber atom.

EXAFS spectroscopy has evolved as a powerful technique to analyze materials lacking long-range crystalline order, such as amorphous materials, thin films, liquids, etc. ${ }^{8,9}$ Element-specific structural information can be obtained from the modulations of the X-ray absorption coefficient: Photoelectrons excited by X-ray absorption are backscattered from atoms in the first few neigh-

(8) Teo, B. K. EXAFS: Basic Principles and Data Analysis; Springer: Berlin, 1986

(9) Koningsberger, D. C., Prins, R., Ed. X-Ray Absorption: Principles, Applications, Techniques of EXAFS, SEXAFS and XANES; Wiley: New York, 1987. 
boring shells. The resulting interference pattern of the absorption coefficient contains information about the number and nature of the surrounding neighbors as well as their distances to the absorber atom. A radial distribution function is obtained through Fourier transformation of the normalized EXAFS modulation from momentum space $\left(k, \AA^{-1}\right)$ into the distance space $(r, \AA)$.

Supported bimetallic catalysts containing a variety of transition metals have been studied with EXAFS, e.g., $\mathrm{Cu}-\mathrm{Ru},-\mathrm{Os},-\mathrm{Rh}$, -Pd; Ir-Pt, $-\mathrm{Rh} ;{ }^{10} \mathrm{Rh}-\mathrm{Co} ;{ }^{11,12} \mathrm{Ni}-\mathrm{Cu} ;{ }^{13}$ and $\mathrm{Pt}-\mathrm{Mo} .^{14}$ In many cases, the formation of alloys was observed, and frequently the bulk composition differed from that on the surface. A common problem encountered with supported metal particles is the migration and agglomeration of the metal phase at high-reduction and/or -reaction temperatures. It was proposed by Yermakov and co-workers that the introduction of a second nonreducible transition metal could limit undesired agglomeration by Coulomb interactions with the noble catalyst metal. The reduced transition metal would be "chemically anchored" to the support through an $\mathrm{M}^{n+}-\mathrm{M}^{0}$ interaction. Sachtler and co-workers suggested that such an effect was responsible for their observation of reduced particle sizes when Fe was added to Pt supported in zeolite Y.15 They found a similar increase in metal dispersion when chromium was coexchanged into rhodium zeolites, and EXAFS measurements at the $\mathrm{Rh} \mathrm{K}$-Edge indicated an interaction between chromium ions and $\mathrm{Rh}$ particles. ${ }^{16}$

There are only few EXAFS studies where a potential anchoring effect by a second metal was examined directly by probing the local environment around both metal constituents. Tin(II) ions in an $\mathrm{Sn} / \mathrm{Pt}$-alumina system were reported to be located at the interface between the support and $\mathrm{Pt}(0)$ clusters. ${ }^{17}$ A similar interaction was found for $\mathrm{Fe}^{3+}$ and $\mathrm{Rh}^{0}$ on silica at $\mathrm{Fe} / \mathrm{Rh}$ ratios up to $0.3 .^{18}$ Higher ratios resulted in the reduction of iron to $\mathrm{Fe}^{0}$ which covered the surface of the rhodium particles. Both reports describe systems reduced at high temperatures. Our recent EXFAS studies of a related Co/Pd coexchanged zeolite system showed that improved dispersion is not caused by chemical anchoring but by a modified cation distribution that affects the reducibility of the palladium ions. ${ }^{19}$ In order to clarify the origin of the effects of a nonreducible second metal, we report an investigation of the interaction between iron and palladium cations coexchanged into zeolite $Y$. The preparation of small palladium particles in a zeolite matrix has been subject of many studies. TPD-MS and thermogravimetric analysis (TGA) of the reduction mechanism of $\left[\mathrm{Pd}\left(\mathrm{NH}_{3}\right)_{4}\right]^{2+}$ in zeolite $\mathrm{X}$ and $\mathrm{Y}$ showed that an autoreduction process, caused by the decomposing ammine ligands, can be suppressed with oxygen atmosphere during the dehydration step. ${ }^{20,21}$ Bergeret et al. observed that a pretreatment between 570 and $870 \mathrm{~K}$ in oxygen and subsequent reduction at low temperature leads to atomic dispersion of a portion of the palladium..$^{22}$ EXAFS studies demonstrated the formation of small metal particles when the $\mathrm{Pd}(\mathrm{II})$-exchanged zeolite was dehydrated under

(10) Sinfelt, J. H.; Via, G. H.; Lytle, F. W. Catal. Rev.-Sci. Eng. 1984 26. 81 .

(11) Van'T Blik, H. F. J.; Koningsberger, D. C.; Prins, R. J. Catal. 1986 97,210 .

(12) Yokoyama, T.; Yamazaki, K.; Kosugi, N.; Kuroda, H.; Ichikawa, M.; Fukushima, T. J. Chem Soc., Chem. Commun. 1984, 962.

(13) Sankar, G.; Vasudevan. S.; Rao, C. N. R. J. Phys. Chem. 1986, 90 , 5325 .

(14) Samant, M. G.; Bergeret, G.; Meitzner, G.; Gallezot, P.; Boudart, M. J. Phys. Chem. 1988, 92, 3547. 231 .

(15) Tzou, M. S.; Jiang, H. J.; Sachtler, W. M. H. Appl. Catal. 1986, 20

(16) Tzou, M. S.: Teo, B. K.; Sachtler, W. M. H. Langmuir 1986, 2, 773 (17) Meitzner, G.; Via, G. H.; Lytle, F. W.; Fung, S. C.; Sinfelt, J. H. J. Phys. Chem. 1988, 92, 2925.

(18) Ichikawa, M.; Fukushima, T.; Yokoyama, T.; Kosugi, N.; Kuroda H. J. Phys. Chem. 1986, 90,1222 .

(19) Moller, K.; Bein, T. Studies in Surface Science and Catalysis.

Zeolites: Facts, Figures, Future; Jacobs, P. A., van Santen, R. A., Eds. Elsevier: Amsterdam, 1989; Vol. 49, p 985.

(20) Exner, D.; Jaeger, N.; Moller, K.; Schulz-Ekloff, G. J. Chem. Soc., Faraday Trans. I 1982, 78, 3537.

(21) Reagan, W. J.; Chester, A. W.; Kerr, G. T. J. Catal. 1981, 69, 89

(22) Bergeret, G.; Gallezot, P.; Imelik, B. J. Phys. Chem. 1981, 85, 411 vacuum, while oxygen treatment resulted in the coordination of palladium cations to the zeolite surface. ${ }^{23}$ It was found that palladium clusters of $2-4$ atoms were stabilized by the zeolite X matrix. ${ }^{24}$ In the present study, we compare the reduction and $\mathrm{Pd}$ particle formation in $\mathrm{Pd}-\mathrm{Y}$ zeolite with the corresponding bimetallic $\mathrm{Fe} / \mathrm{Pd}-\mathrm{Y}$ systems to explore a possible influence of the iron phase on the reduction and agglomeration behavior of $\mathrm{Pd}$. We follow the changes in oxidation state and coordination environment of both constituents during reduction by monitoring the iron and palladium K-edge absorption spectra. This approach provides the maximal information about any possible interaction of both constituents.

\section{Experimental Section}

Five different zeolite sample sets based upon zeolite Y (Linde LZ-Y52) were used in this study. Single-metal-exchanged samples were prepared as follows: Zeolite $P \boldsymbol{d}-Y$ was obtained by aqueous cation exchange with $\left[\mathrm{Pd}\left(\mathrm{NH}_{3}\right)_{4}\right]^{2+}(0.01 \mathrm{M})$. Sample $\mathrm{Fe}-\mathrm{Y}$ was prepared by an anaerobic exchange with $\mathrm{FeSO}_{4}(0.01 \mathrm{M})$ in degassed, slightly acidified water $(\mathrm{pH}=4)$. The samples were washed, filtered, and subsequently dehydrated in a flow of oxygen at $623 \mathrm{~K}$, at a heating rate of $1 \mathrm{~K} / \mathrm{min}$. After evacuation, small portions of the samples were reduced with hydrogen at room temperature (600 Torr) and at 423 and $623 \mathrm{~K}$ in a flow reactor.

Zeolites containing $\mathrm{Pd}$ and $\mathrm{Fe}$ were prepared according to three different sequences: Sample $F e P d-Y$ resulted from hydrated $\mathrm{Fe}-\mathrm{Y}$ that was subsequently exchanged with $\left[\mathrm{Pd}\left(\mathrm{NH}_{3}\right)_{4}\right]^{2+}$. Sample $\mathrm{Fe}^{\mathrm{III}} \mathrm{Pd}-Y$ was derived from $\mathrm{Fe}-\mathrm{Y}$, dehydrated at $623 \mathrm{~K}$ under oxygen, and subsequently ion-exchanged with $\left[\mathrm{Pd}\left(\mathrm{NH}_{3}\right)\right]_{4}{ }^{2+}$. Sample $P d F e-Y$ was prepared in the reversed sequence, i.e., after exchanging with $\mathrm{Pd}^{2+}$ the zeolite was dehydrated in an oxygen flow at $475 \mathrm{~K}$ and subsequently exchanged with $\mathrm{FeSO}_{4}$ under anaerobic conditions. All three sample sets were degassed under oxygen at $623 \mathrm{~K}$, evacuated, and reduced with hydrogen at 295 , 423 , and $623 \mathrm{~K}$. Subsequent evacuation was performed at the reduction temperatures to pressures smaller than $10^{-3}$ Torr. Sample Fe $\mathrm{F}^{\mathrm{III}} \mathrm{Pd}-\mathrm{Y}$ was also reduced at $823 \mathrm{~K}$.

Chemical analysis (Galbraith Laboratories) gave the following zeolite unit cell compositions:

$$
\begin{array}{ll}
\mathrm{Fe}-\mathrm{Y} & \mathrm{Na}_{45} \mathrm{Fe}_{6}\left(\mathrm{AlO}_{2}\right)_{57}\left(\mathrm{SiO}_{2}\right)_{135} \\
\mathrm{Pd}-\mathrm{Y} & \mathrm{Na}_{33} \mathrm{Pd}_{12}\left(\mathrm{AlO}_{2}\right)_{57}\left(\mathrm{SiO}_{2}\right)_{135} \\
\mathrm{Fe}^{\mathrm{III}} \mathrm{Pd}-\mathrm{Y} & \mathrm{Na}_{18} \mathrm{Fe}_{8.7} \mathrm{Pd}_{10}\left(\mathrm{AlO}_{2}\right)_{57}\left(\mathrm{SiO}_{2}\right)_{135} \\
\mathrm{PdFe}-\mathrm{Y} & \mathrm{Na}_{29} \mathrm{Fe}_{3.8} \mathrm{Pd}_{10}\left(\mathrm{AlO}_{2}\right)_{57}\left(\mathrm{SiO}_{2}\right)_{135}
\end{array}
$$

Zeolite powders were embedded in an octadecane/eicosane mixture and kept under nitrogen atmosphere until the EXAFS measurements were carried out. EXAFS experiments were performed at the X-11A beam line at NSLS (Brookhaven $\mathrm{Na}$ tional Laboratory) with an electron energy of $2.5 \mathrm{GeV}$ and ring currents between 40 and $120 \mathrm{~mA}$. Data were collected with a $\mathrm{Si}(400)$ crystal pair monochromator at the Pd K-edge (24350 $\mathrm{eV})$ and with a Si(111) monochromator at the Fe K-edge (7112 $\mathrm{eV}$ ) at $100 \mathrm{~K}$. Samples Fe ${ }^{\mathrm{III}} \mathrm{Pd}-\mathrm{Y}$ (reduced at 623 and $873 \mathrm{~K}$ ) and $\mathrm{PdFe}-\mathrm{Y}$ (reduced at $623 \mathrm{~K}$ ) were measured at the Pd K-edge at a later time at $\mathrm{X}-11 \mathrm{~A}$ with a $\mathrm{Si}(111)$ monochromator. Data analysis was performed following standard procedures. ${ }^{25}$ Backscattering amplitude and phase functions used in the least-squares fitting routine were extracted from the following reference materials and used as listed (see text): $P d$ foil $(\mathrm{fcc})$, lst Pd-Pd shell, $N=12, R=2.744 \AA$; 3 rd Pd-Pd shell, $N=24$, $R=4.76 \AA ; 4$ th Pd-Pd shell, $N=12, R=5.50 \AA ; 7$ th Pd-Pd shell, $N=8, R=7.26 \AA ; P d O$ powder (tetragonal), $\mathrm{Pd}-\mathrm{O}, N$ $=4, R=2.017 \AA ; F e^{\mathrm{III}}$ acac (acac = acetylacetonate), $\mathrm{Fe}-\mathrm{O}, N$ $=6, R=1.992 \AA ; F e O$ powder $(\mathrm{NaCl}$ structure $), \mathrm{Fe}-\mathrm{Fe}, N=$ $12, R=3.063 \AA ; M n S$ powder $(\mathrm{NaCl}$ structure $), \mathrm{Mn}-\mathrm{S}$ for $\mathrm{Fe}-\mathrm{Si}$, $N=6, R=2.61 \AA$; Co powder (hep), Co-Co for Pd-Fe, $N=$ $12, R=2.514 \AA$.

(23) Moller, K.; Bein, T. J. Phys. 1986, C8, 231. 6116.

(24) Moller, K.; Koningsberger, D. C.; Bein, T. J. Phys. Chem. 1989, 93 ,

(25) Lee, P. A.; Citrin, P. H.; Eisenberger, P.; Kincaid, B. M. Rev. Mod. Phys. 1981, 53, 769 

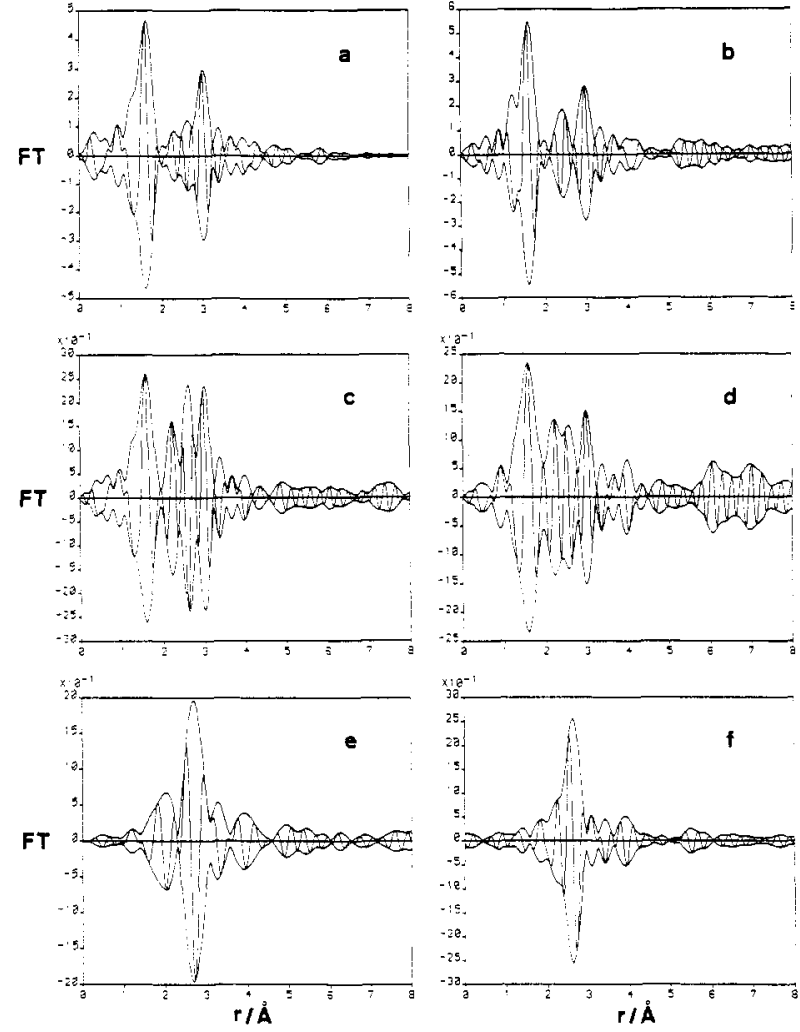

Figure 1. $k^{3}$-Weighted Fourier transforms of the Pd-edge of sample $\mathrm{Pd}-\mathrm{Y}(\mathrm{a}, \mathrm{c}, \mathrm{e})$ and $\mathrm{Fe} \mathrm{e}^{\mathrm{III}} \mathrm{Pd}-\mathrm{Y}(\mathrm{b}, \mathrm{d}, \mathrm{f})$ after dehydration under oxygen atmosphere at $623 \mathrm{~K}(\mathrm{a}, \mathrm{b})$ and hydrogen reduction at room temperature $(c, d)$ and $423 \mathrm{~K}(\mathrm{e}, \mathrm{f})$.

\section{Results and Discussion}

$P d-E d g e E X A F S$. In Figure 1, the EXAFS spectra of palladium-exchanged zeolites $\mathrm{Pd}-\mathrm{Y}$ (parts a, $\mathrm{c}$, and e) are compared to those of FellIPd-Y, which were iron-exchanged, dehydrated in oxygen, and subsequently exchanged with palladium (parts b, $d$, and $f$ ). Spectra of PdFe-Y are very similar to those of $\mathrm{Fe}^{\mathrm{III}} \mathrm{Pd}-\mathrm{Y}$ and are therefore not included. Structural parameters obtained from the data analysis are listed in Table I. The Fourier transforms were $k^{3}$-weighted over a range of $2.8-14 \AA^{-1}$ and show the samples after treatment at $632 \mathrm{~K}$ in oxygen atmosphere, reduction with hydrogen at room temperature, and reduction at $423 \mathrm{~K}$. Peak positions are not corrected for phase shift effects $(0.3-0.5 \AA)$, but true bond distances are obtained from the fitting process with model compounds.

Dehydration under Oxygen Atmosphere. Samples measured directly after ion exchange show the same ligand environment of $\mathrm{Pd}$ as the aqueous precursor ion $\left[\mathrm{Pd}\left(\mathrm{NH}_{3}\right)_{4}\right]^{2+}$, as described earlier ${ }^{23}$ (spectra not shown). Upon dehydration under oxygen atmosphere, the ammine ligands are split off and the palladium cations coordinate to the zeolite lattice. This is demonstrated in parts $a$ and $b$ of Figure 1 for samples $P d-Y$ and Fe $e^{\text {Ill }} P d-Y$, where the first strong peak represents the oxygen atoms of $\mathrm{Pd}-\mathrm{O}$ atom pairs. The palladium ions are coordinated on average to 2.8 nearest oxygens in both samples with a bond length of $1.99 \AA$. Concomitant to the oxygen peak, an outer-shell contribution appears at about $3 \AA$ (uncorrected). Back-transformation and inspection of the amplitude function reveals that it originates from a light element, such as $\mathrm{Si}$ or $\mathrm{Al}$ atoms from the zeolite framework. Similar observations have been made upon dehydration of other cation-exchanged zeolites, and this feature can be considered as an indication for the migration of cations into defined coordination sites in the zeolite framework. ${ }^{26-28}$

(26) Morrison, T. I.; Iton, L. E.; Shenoy, G. K.; Stucky, G. D.; Suib, S L.; Reis, A. H. J. Chem. Phys. 1980, 73, 4705.

(27) Herron, N.; Wang, Y.; Eddy, M. M.; Stucky, G. D.; Cox, D. E.; Moller, K.; Bein, T. J. Am. Chem. Soc. 1989, 111, 530.

(28) Woolery, G.; Kuehl, G.; Chester, A.; Bein, T.; Stucky, G.; Sayers, D. E. J. Phys. 1986, C8, 281 .
TABLE I: Structural Data As Derived from EXAFS Analysis, Pd Absorption Edge

\begin{tabular}{|c|c|c|c|c|c|}
\hline sample & atom pair & $R^{a} / \AA$ & $N^{b}$ & $\Delta \sigma^{2 c} / \AA^{2}$ & $\Delta E^{d} / \mathrm{eV}$ \\
\hline \multicolumn{6}{|c|}{$623 \mathrm{~K}$ Oxygen } \\
\hline$P d-Y$ & $\mathrm{Pd}-\mathrm{OZ}$ & 1.99 & 2.8 & 0.000 & -0.1 \\
\hline $\mathrm{Fe}^{\mathrm{III}} \mathrm{Pd}-\mathrm{Y}$ & $\mathrm{Pd}-\mathrm{OZ}$ & 1.99 & 2.9 & 0.000 & -0.1 \\
\hline & Pd-Pd & 2.78 & 0.5 & 0.000 & +11.9 \\
\hline $\mathrm{PdFe}-\mathrm{Y}$ & $\mathrm{Pd}-\mathrm{OZ}$ & 1.98 & 3.2 & 0.000 & +1.8 \\
\hline $\mathrm{CoPd}-\mathrm{Y}$ & $\mathrm{Pd}-\mathrm{OZ}$ & 1.98 & 2.8 & 0.000 & +1.7 \\
\hline \multicolumn{6}{|c|}{$295 \mathrm{~K}$ Hydrogen } \\
\hline$P d-Y$ & $\mathrm{Pd}-\mathrm{OZ}$ & $1.98^{\circ}$ & 1.9 & 0.002 & -1.6 \\
\hline $\mathrm{Fe}^{\mathrm{III}} \mathrm{PdY}$ & $\mathrm{Pd}-\mathrm{OZ}$ & 1.99 & 1.4 & 0.000 & -0.1 \\
\hline $\mathrm{PdFe}-\mathrm{Y}$ & $\mathrm{Pd}-\mathrm{OZ}$ & 1.99 & 1.2 & 0.000 & -0.4 \\
\hline CoPd-Y & $\mathrm{Pd}-\mathrm{OZ}$ & 2.00 & 1.2 & 0.000 & -1.6 \\
\hline & 3. $\mathrm{Pd}-\mathrm{Pd}$ & 4.77 & 3.2 & 0.001 & -5.2 \\
\hline & 4. $\mathrm{Pd}-\mathrm{Pd}$ & 5.47 & 1.2 & 0.000 & +0.6 \\
\hline & 7. $\mathrm{Pd}-\mathrm{Pd}$ & 7.27 & 0.8 & 0.000 & -2.2 \\
\hline \multicolumn{6}{|c|}{$423 \mathrm{~K}$ Hydrogen } \\
\hline $\mathrm{Pd}-\mathrm{Y}^{e}$ & 1. $\mathrm{Pd}-\mathrm{Pd}$ & 2.80 & 2.2 & 0.009 & -1.0 \\
\hline $\mathrm{Fe}^{\mathrm{III} P d-Y}$ & 1. $\mathrm{Pd}-\mathrm{Pd}$ & 2.83 & 2.6 & 0.007 & +2.2 \\
\hline PdFe-Y & 1. $\mathrm{Pd}-\mathrm{Pd}$ & 2.83 & 3.1 & 0.008 & +3.0 \\
\hline CoPd-Y & 1. $\mathrm{Pd}-\mathrm{Pd}$ & 2.74 & 2.3 & 0.001 & -0.2 \\
\hline & 3. $\mathrm{Pd}-\mathrm{Pd}$ & 4.76 & 3.3 & 0.001 & -3.7 \\
\hline & 4. $\mathrm{Pd}-\mathrm{Pd}$ & 5.45 & 1.5 & 0.001 & -4.7 \\
\hline & 7. $\mathrm{Pd}-\mathrm{Pd}$ & 7.28 & 0.8 & 0.001 & -6.2 \\
\hline \multicolumn{6}{|c|}{$623 \mathrm{~K}$ Hydrogen } \\
\hline$P d-Y^{e}$ & 1. $\mathrm{Pd}-\mathrm{Pd}$ & $2.74^{\circ}$ & 8.0 & 0.001 & -5.9 \\
\hline & 3. $P d-P d$ & 4.75 & 9.5 & 0.001 & -3.4 \\
\hline & 4. $\mathrm{Pd}-\mathrm{Pd}$ & 5.50 & 4.1 & 0.001 & -6.4 \\
\hline & 7. $\mathrm{Pd}-\mathrm{Pd}$ & 7.26 & 1.6 & 0.004 & -3.7 \\
\hline \multirow[t]{2}{*}{$\mathrm{Fe}^{\mathrm{III}} \mathrm{Pd}-\mathrm{Y}$} & 1. $\mathrm{Pd}-\mathrm{Pd}$ & 2.73 & 8.8 & 0.004 & -5.2 \\
\hline & 3. $\mathrm{Pd}-\mathrm{Pd}$ & 4.76 & 8.0 & 0.003 & -7.7 \\
\hline $\mathrm{PdFe}-\mathrm{Y}$ & 1. $\mathrm{Pd}-\mathrm{Pd}$ & 2.72 & 7.7 & 0.004 & -2.2 \\
\hline \multirow[t]{4}{*}{ CoPd-Y } & 1. $\mathrm{Pd}-\mathrm{Pd}$ & 2.75 & 5.0 & 0.001 & -7.0 \\
\hline & 3. $\mathrm{Pd}-\mathrm{Pd}$ & 4.77 & 7.6 & 0.002 & -7.4 \\
\hline & 4. $\mathrm{Pd}-\mathrm{Pd}$ & 5.50 & 3.7 & 0.002 & -4.4 \\
\hline & 7. $\mathrm{Pd}-\mathrm{Pd}$ & 7.29 & 1.2 & 0.000 & -7.1 \\
\hline \multicolumn{6}{|c|}{$723 \mathrm{~K}$ Hydrogen } \\
\hline $\mathrm{Fe}^{\mathrm{III}} \mathrm{Pd}-\mathrm{Y}$ & 1. $\mathrm{Pd}-\mathrm{Pd}$ & $2.73^{\circ}$ & 8.6 & 0.003 & -4.3 \\
\hline
\end{tabular}

${ }^{a}$ Bond distances: accuracy, $\pm 0.01 \AA .{ }^{b}$ Coordination numbers: accuracy, $\pm 10-20 \%$. ' Deviations of the Debye-Waller factor: accuracy, $\pm 10-20 \%$. 'Deviations from the inner potential. 'The accuracy for the Pd-Pd atom pairs in sample PD-Y is $10 \%$ for $N$ and $\Delta \sigma^{2}$.

The oxygen neighbors of the palladium cations in sample $\mathrm{Pd}-\mathrm{Y}$ and $\mathrm{Fe}^{\mathrm{III}} \mathrm{Pd}-\mathrm{Y}$ are labeled $\mathrm{Pd}-\mathrm{OZ}$, where $\mathrm{OZ}$ stands for zeolite oxygen. The fit results suggest that the palladium ions are coordinated to three framework oxygens. This corresponds to cation siting in $\mathrm{SI}^{\prime}$ (or SII, $\mathrm{SII}^{\prime}$ ) positions in six-ring $\mathrm{Si} / \mathrm{Al}$ windows of the zeolite lattice. X-ray diffraction studies of similarly treated $\mathrm{Pd}-\mathrm{Y}$ zeolites revealed $\mathrm{Pd}^{2+}-\mathrm{OZ}$ bond distances between 2.01 and $2.07 \AA$ with all located cations in $\mathrm{SI}^{\prime}$ positions. ${ }^{29,30}$ We observe a slight difference between Fe $\mathrm{F}^{\mathrm{III}} \mathrm{Pd}-\mathrm{Y}$ and the Pd-exchanged sample Pd-Y. A small peak at about $2.5 \AA$ can be isolated in $\mathrm{Fe}^{\mathrm{III}} \mathrm{Pd}-\mathrm{Y}$ and fitted with the palladium foil reference. It indicates the onset of palladium reduction even under an oxidizing atmosphere. A Pd-Pd scatterer pair with a bond distance of $2.78 \AA$ and average coordination number of 0.5 is found (Table I).

Reduction at Room Temperature. After reduction of $\mathrm{Pd}-\mathrm{Y}$ and $\mathrm{Fe}^{\mathrm{III}} \mathrm{Pd}-\mathrm{Y}$ at room temperature (Figure $\mathrm{lc}, \mathrm{d}$ ), a more complex picture arises. Both samples still show the peaks corresponding to $\mathrm{Pd}-\mathrm{OZ}$ and $\mathrm{Pd}-\mathrm{Si} / \mathrm{Al}$ contributions (note the smaller scale), but these are now obscured by other features with intermediate distances. The average $\mathrm{Pd}-\mathrm{OZ}$ coordination number is reduced to 1.9 in $\mathrm{Pd}-\mathrm{Y}$ and to 1.4 in $\mathrm{Fe} \mathrm{el}^{\mathrm{lll}} \mathrm{Pd}-\mathrm{Y}$, while the bond distance remains at $1.99 \AA$. This is readily interpreted with a partial reduction of the $\mathrm{Pd}^{2+}$ ions to $\mathrm{Pd}^{0}$. Provided that the unreduced $\mathrm{Pd}^{2+}$ ions remain bonded to these oxygen atoms, the degree of reduction can be calculated. Hence, about $35 \%$ of all $\mathrm{Pd}$ ions have

(29) Bergeret, G.; Tran Manh Tri; Gallezot, P. J. Phys. Chem. 1983, 87, 1160

(30) Gallezot, P.; Imelik, B. Adv. Chem. Ser. 1973, 121, 66-73. 

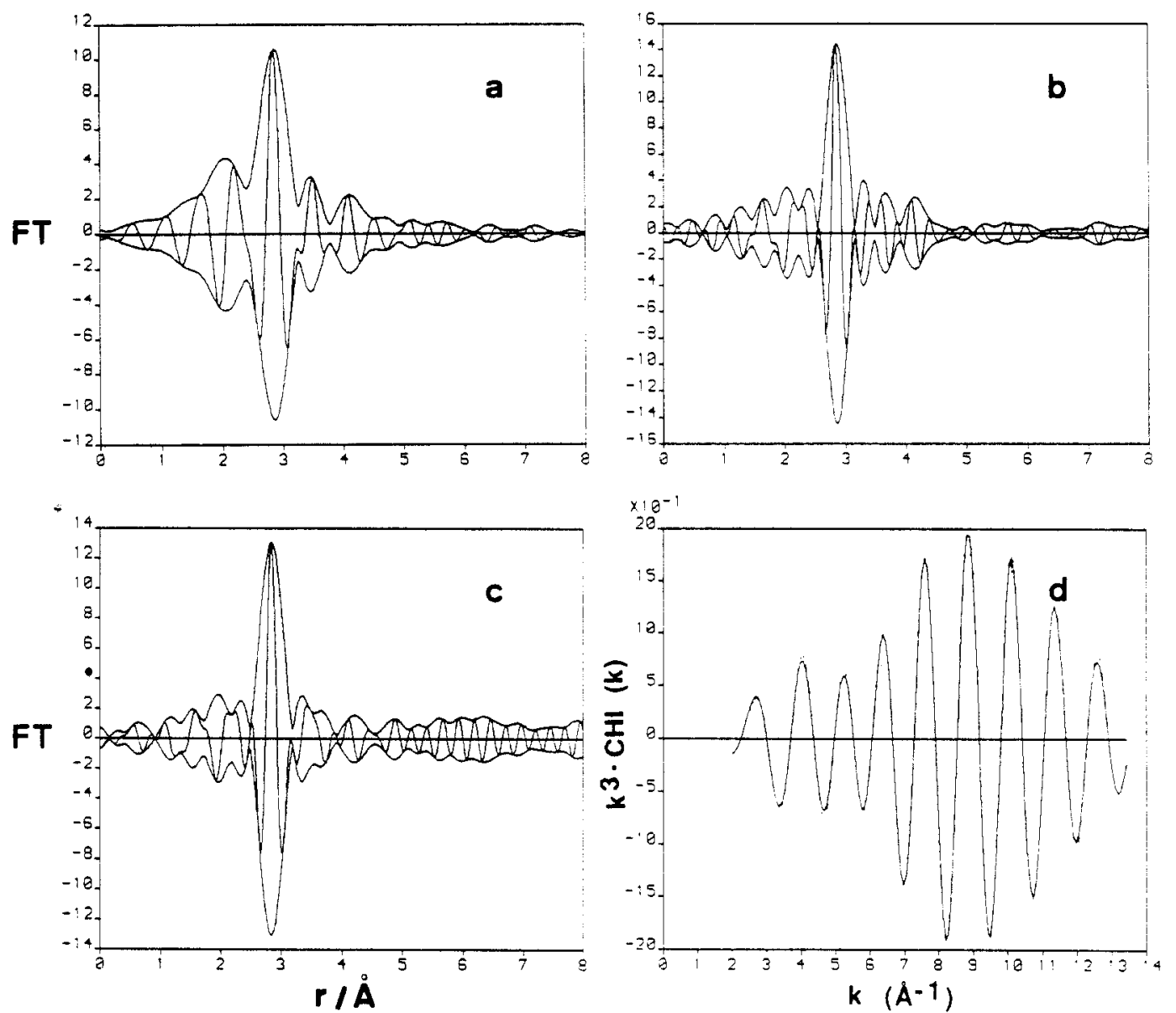

Figure 2. Phase- and amplitude-corrected Fourier transforms ( $k^{3}$-weighted; corrected with Pd foil) of Pd-edge spectra after reduction at room temperature of (a) Pd-Y, (b) Fe $e^{I I I P d}-Y$, , c) PdFe-Y, and (d) $k^{3}$-weighted, isolated Pd-Pd EXAFS contribution of PdFe-Y (solid line) and fit (broken line).

been reduced in sample $\mathrm{Pd}-\mathrm{Y}$. The presence of iron increases the degree of reduction to about $55 \%$ in sample $\mathrm{Fe} \mathrm{e}^{\mathrm{III}} \mathrm{Pd}-\mathrm{Y}(60 \%$ in $\mathrm{PdFe}-\mathrm{Y})$. The additional peaks in the distribution junction can be explained by interactions of these reduced metal atoms with the zeolite.

Reduction at $423 \mathrm{~K}$. Drastic changes occur when the samples $\mathrm{Pd}-\mathrm{Y}$ and $\mathrm{Fe}{ }^{\mathrm{III}} \mathrm{Pd}-\mathrm{Y}$ are treated at $423 \mathrm{~K}$ under hydrogen (Figure le,f). The oxygen contribution at $1.99 \AA$ has totally vanished, indicating complete reduction of the palladium phase. New Pd-Pd interactions are visible in a peak at about $2.7 \AA$ (uncorrected). The magnitude of this interaction is extremely small compared to bulk metal, indicating the formation of molecule-sized palladium clusters. No outer coordination shells associated with bulk palladium are detectable. However, small features on both sides of the Pd peak are observed in Pd-Y. An almost identical distribution function was obtained for $\mathrm{Pd}-\mathrm{X}$ zeolites when reduced at room temperature, which has been described in detail. ${ }^{24}$ The additional small peaks were found to arise from interactions of the palladium clusters with the stabilizing zeolite matrix in the form of a long Pd--OZ bond with a distance of $2.76 \AA$ and a Pd--Si distance of $3.44 \AA$. Model calculations of the cluster arrangements show that two to four Pd atoms are arranged in the sodalite subunits in $\mathrm{SI}^{*}$ and $\mathrm{SII}^{*}$ positions, having a bond length $\mathrm{Pd}-\mathrm{OZ}>2.65 \AA$ while detecting each other at a distance of $2.75 \AA$. A similar arrangement of reduced palladium atoms is apparent in sample $\mathrm{Pd}-\mathrm{Y}$ with an average $\mathrm{Pd}-\mathrm{Pd}$ coordination number of 2.2. The bond distance of $2.80 \AA$ exceeds the value for bulk palladium by $0.05 \AA$, which is in contrast to the bond contraction usually found for small metal particles of ca. 10-20 $\AA$ diameter ${ }^{31,32}$ Lattice expansions can be found in bulk metal hydrides or borides. ${ }^{33,34}$ We can exclude the formation of bulk L63i:

(31) Moraweck, B.: Clugnet, G.; Renouprez, A. J. Surf. Sci. 1979, 81,

(32) Moraweck, B.; Renouprez. A. Surf. Sci. 1981, 106, 35 palladium hydride since clearly no bulk palladium is present (no outer shells, very small coordination numbers in the first shell). Furthermore, under the chosen experimental conditions (vacuum, elevated temperatures), a hydride phase would thermodynamically not be stable. As described above, the sodalite unit represents an ideal matrix for stabilizing palladium atoms in six-ring positions, giving rise to the formation of small ensembles with unusual bond distances.

In Fe ${ }^{I I I} \mathrm{Pd}-\mathrm{Y}$ (and PdFe-Y) the oxygen interface interactions are less pronounced. The absence of the "satellite peaks" in iron-exchanged samples is more apparent in Figure 2. Here, amplitude- and phase-corrected Fourier transformations (with palladium foil as reference) are shown for Pd-Y, Fe ${ }^{I I I} \mathrm{Pd}-\mathrm{Y}$ and $\mathrm{PdFe}-\mathrm{Y}$. A shift of $5 \mathrm{eV}$ was sufficient to position the imaginary part in the maximum of the magnitude. Totally symmetric peaks are obtained for the Pd-Pd atom pairs, while the influence of the zeolite interface is best visible in $\mathrm{Pd}-\mathrm{Y}$ (Figure 2a). A backtransformation was applied on sample Fe ${ }^{\text {III }} \mathrm{Pd}-\mathrm{Y}$ and $\mathrm{PdFe}-\mathrm{Y}$ between 2.5 and $3.2 \AA$, dividing out the applied corrections. Excellent fits were thus obtained for the Pd-Pd interaction of which one example is shown for $\mathrm{PdFe}-\mathrm{Y}$ in Figure $2 \mathrm{~d}$ (note the almost complete match between fit and experimental data). Coordination numbers of $2.6\left(\mathrm{Fe}^{\mathrm{III}} \mathrm{Pd}-\mathrm{Y}\right)$ and 3.1 ( $\left.\mathrm{PdFe}-\mathrm{Y}\right)$ are slightly increased with respect to 2.2 for $\mathrm{Pd}-\mathrm{Y}$, as are the bond distances (2.83 $\AA$ for $\mathrm{Fe}^{\mathrm{III}} \mathrm{Pd}-\mathrm{Y}$ and $\mathrm{PdFe}-\mathrm{Y}, 2.80 \AA$ for $\mathrm{Pd}-\mathrm{Y}$ ). These fit results emphasize that no additional phase besides Pd-Pd is present in the bimetal-exchanged zeolite samples when reduced at $423 \mathrm{~K}$. It further suggests that, when bimetal-exchanged, on the average less $\mathrm{Pd}$ atoms are present that interact with the zeolite matrix. Small metal clusters do exist that are less densely packed than bulk palladium.

(33) Lengeler, B. Phys. Rev. Lett. 1984, 53, 74

(34) Lengeler, B. Solid State Commun. 1985, 55, 679 

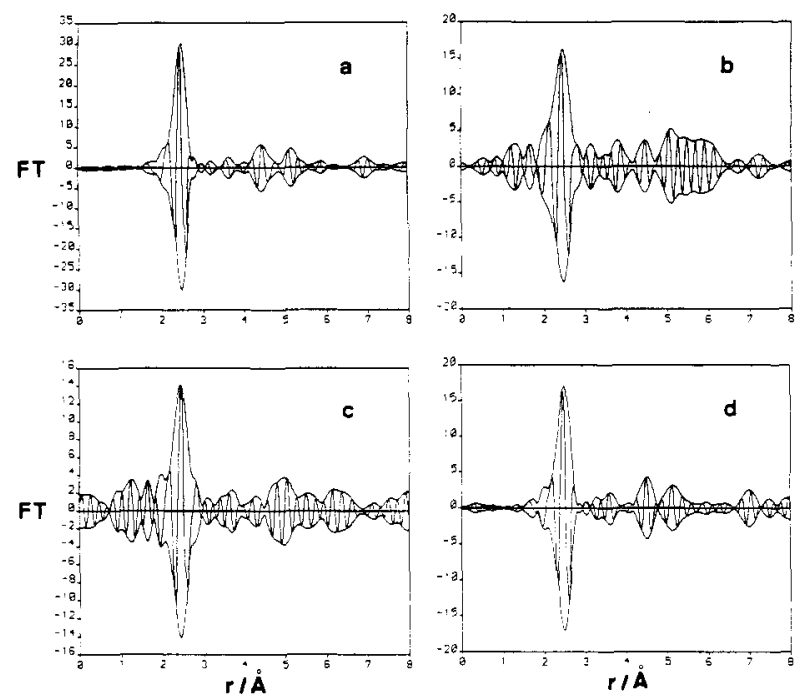

Figure 3. $k^{3}$-Weighted Fourier transform of the Pd-edge of Pd-Y (a), $\mathrm{Fe}^{\mathrm{II}} \mathrm{Pd}-\mathrm{Y}(\mathrm{b}), \mathrm{PdFe}-\mathrm{Y}(\mathrm{c})$ and $\mathrm{CoPd}-\mathrm{Y}$ (d) reduced at $623 \mathrm{~K}$.

Reduction at $623 \mathrm{~K}$. Hydrogen reduction of the $\mathrm{Pd}-$ zeolite samples at $623 \mathrm{~K}$ causes metal aggregation and formation of larger particles as demonstrated in Figure 3. The first Pd shell is strongly increased in $\mathrm{Pd}-\mathrm{Y}$ (note scale) and outer-shell scattering up to the 7 th coordination shell is now visible (Figure 3a). Fit results of the 1st, 3rd, 4th and 7th shells are listed in Table I. All bond distances are now identical with those of bulk palladium within the limits of accuracy. Both iron-containing samples (Figure 3b, $\mathrm{Fe}^{\mathrm{III}} \mathrm{Pd}-\mathrm{Y}$ and $3 \mathrm{c}, \mathrm{PdFe}-\mathrm{Y}$ ) apparently show a smaller first-shell scattering, but data fitting gives similar coordination numbers $N$ of about 8 in all samples. The smaller peak height is caused by a higher static disorder in these samples as compared to Pd-Y.
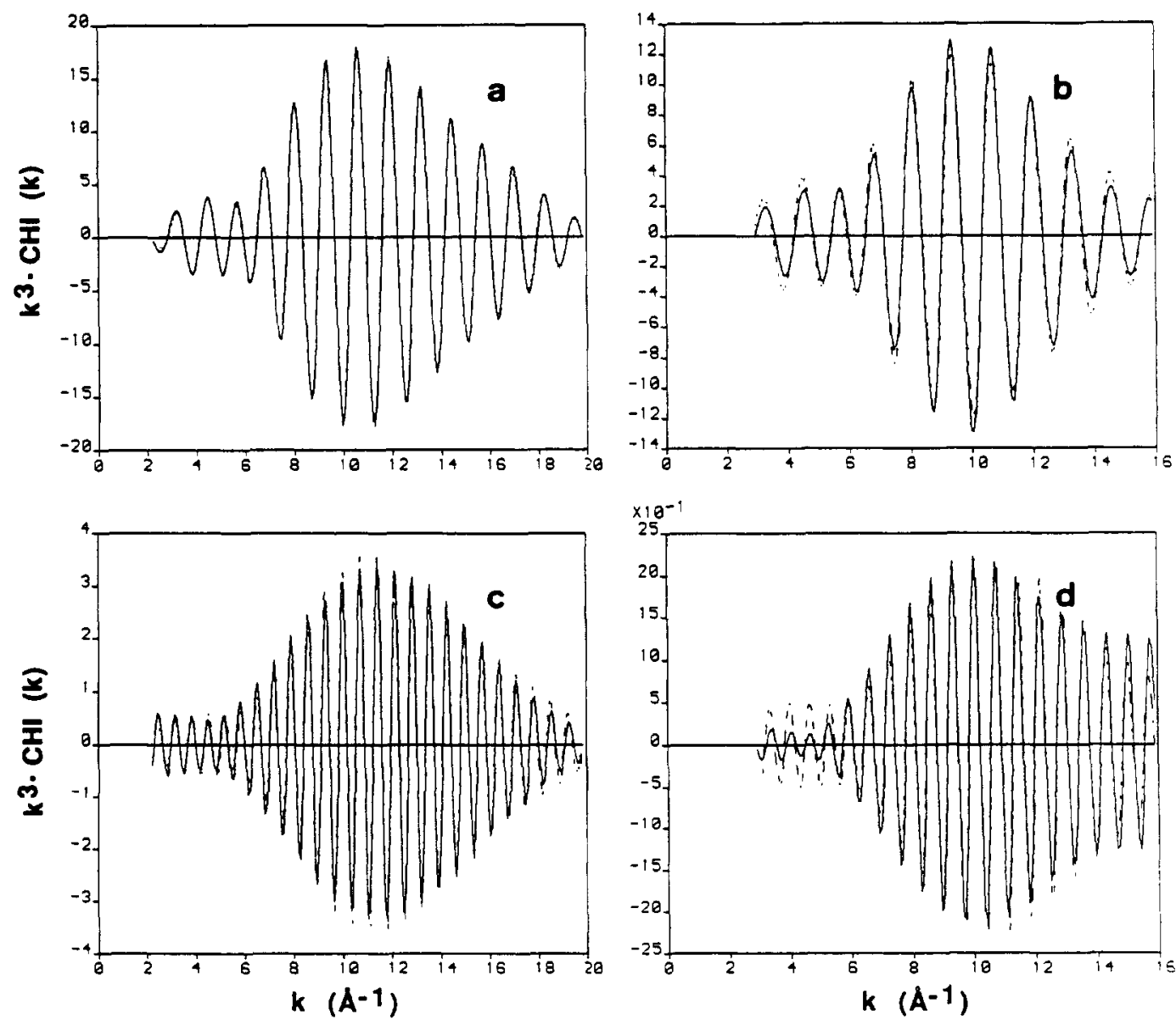

Figure 4. $k^{3}$-Weighted isolated contribution of the 1 st $\mathrm{Pd}$ shell (a,b; solid line) and 3rd $\mathrm{Pd}$ shell (c,d; solid line) of sample $\mathrm{Pd}-\mathrm{Y}$ (a,c) and sample Fe $e^{I I I P d}-\mathrm{Y}(\mathrm{b}, \mathrm{d})$ reduced at $623 \mathrm{~K}$ and fit (broken line, performed with Pd foil as reference). 

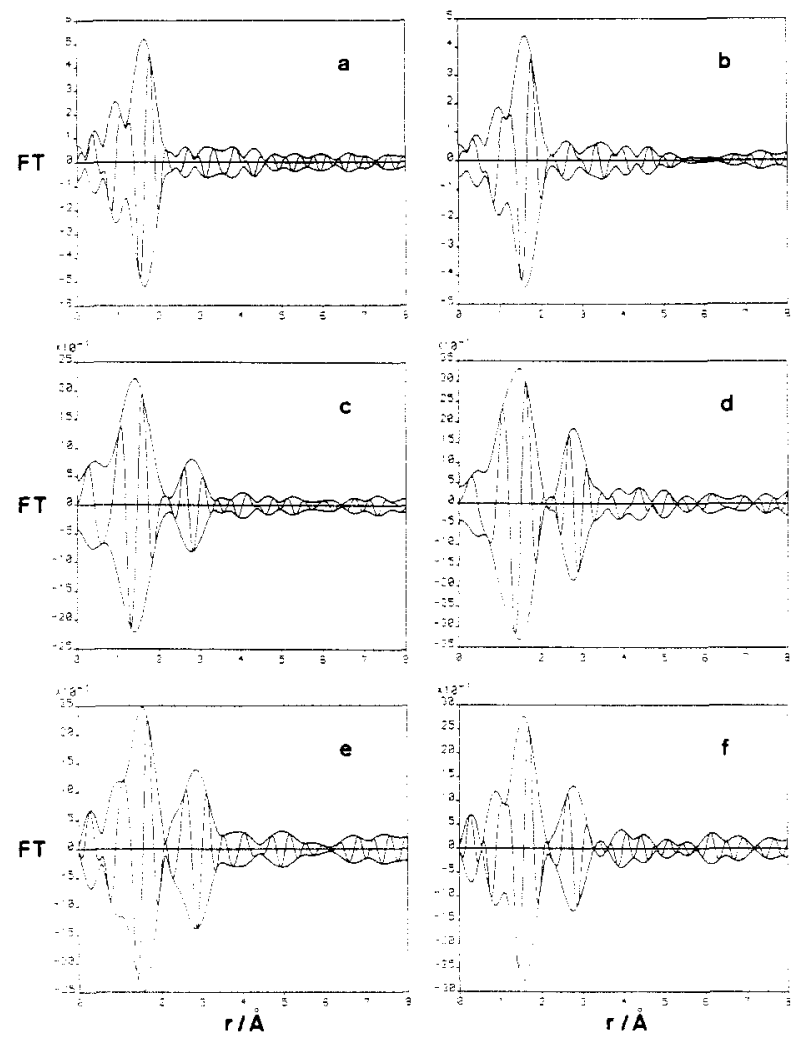

Figure 5. $k^{3}$-Weighted Fourier transform of the Fe-edge of sample $\mathrm{Fe}-\mathrm{Y}$ $(\mathrm{a}, \mathrm{c}, \mathrm{e})$, sample $\mathrm{PdFe}-\mathrm{Y}(\mathrm{b})$, and sample $\mathrm{Fe}^{\mathrm{III}} \mathrm{Pd}-\mathrm{Y}(\mathrm{d}, \mathrm{f})$ after ion exchange $(\mathrm{a}, \mathrm{b}, \mathrm{d})$, dehydration under oxygen atmosphere at $623 \mathrm{~K}(\mathrm{c})$, and hydrogen reduction at $623 \mathrm{~K}(\mathrm{e})$ and $423 \mathrm{~K}(\mathrm{f})$

interaction between palladium and iron is not detectable in the bimetallic zeolites at the Pd edge.

Iron-Edge EXAFS. The above conclusion is best verified by examination of the same samples at the iron absorption edge. Fewer iron ions than palladium atoms are present in the samples and an interaction of these two constituents should therefore be more readily probed at the iron edge. Any $\mathrm{Pd}-\mathrm{Fe}$ interaction should be detected at similar distances as observed at the palladium edge. In Figure 5, the $k^{3}$-weighted Fourier transformations (3.5-11 $\AA$ ) of the bimetal-containing samples are shown and compared to monometallic, iron-exchanged zeolites treated similarly.

Ion-Exchanged $\mathrm{Fe}-\mathrm{Y}$ and $\mathrm{PdFe}-\mathrm{Y}$. EXAFS data of sample $\mathrm{Fe}-\mathrm{Y}$ and $\mathrm{PdFe}-\mathrm{Y}$, obtained after ion exchange, are shown in Figure 5a,b. Only one contribution due to oxygen coordination is visible. When fitted with $\mathrm{Fe}^{\mathrm{III}}$ acac, coordination numbers of 6.5 and a bond length of $2.11 \AA$ (see Table II) suggest the presence of the hexaquo complex $\left[\mathrm{Fe}\left(\mathrm{H}_{2} \mathrm{O}\right)_{6}\right]^{2+}$ in the large cavities of the zeolite framework. This is also supported by the greenish color of the zeolite powder.

Dehydration under Oxygen Atmosphere. When sample Fe-Y is dehydrated in oxygen at $623 \mathrm{~K}$ (Figure $5 \mathrm{c}$ ), the appearance of an outer shell indicates migration of the ions to cation positions in the zeolite framework, as observed for the $\mathrm{Pd}^{2+}$ ions in $\mathrm{Pd}$ containing zeolites at the Pd absorption edge. A back-transformation of this contribution, however, results in an amplitude function that differs from a pure $\mathrm{Fe}-\mathrm{Si} / \mathrm{Al}$ backscattering pair. Since no ideal reference for the analysis of this atom pair exists, an EXAFS reference file was prepared from $\mathrm{MnS}$. The first-shell $\mathrm{Mn}-\mathrm{S}$ coordination with a bond distance of $2.61 \AA$ was used to calculate a scatterer pair $\mathrm{Mn}-\mathrm{S}$ with a bond length of $3.4 \AA$, which is close to the $\mathrm{Fe}-\mathrm{Si}$ distance. Fits with this model compound were only satisfying if an $\mathrm{Fe}-\mathrm{Fe}$ atom pair from the second-coordination sphere of $\mathrm{FeO}$ was included. Best fits were obtained with two iron nearest-neighbors with a bond distance of $3.01 \AA$ and $1.3 \mathrm{Si} / \mathrm{Al}$ atoms at $3.47 \AA$ (see Table II). Thus, only a portion of the iron cations is isolated in cation positions, while the remainder forms very small iron oxide clusters (no additional outer
TABLE II: Structural Data As Derived from EXAFS Analysis, Fe Absorption Edge

\begin{tabular}{|c|c|c|c|c|c|}
\hline sample & atom pair & $R / \AA$ & $N$ & $\Delta \sigma^{2} / \AA^{2}$ & $\Delta E / \mathrm{eV}$ \\
\hline \multicolumn{6}{|c|}{295 K Hydrated } \\
\hline $\mathrm{Fe}-\mathrm{Y}$ & $\mathrm{Fe}-\mathrm{OZ}$ & 2.11 & 6.5 & 0.004 & +0.5 \\
\hline $\mathrm{PdFe}-\mathrm{Y}$ & $\mathrm{Fe}-\mathrm{OZ}$ & 2.11 & 6.4 & 0.007 & +1.9 \\
\hline \multicolumn{6}{|c|}{$623 \mathrm{~K}$ Oxygen } \\
\hline $\mathrm{Fe}-\mathrm{Y}$ & $\mathrm{Fe}-\mathrm{OZ}$ & 1.92 & 3.1 & 0.007 & +1.8 \\
\hline & $\mathrm{Fe}-\mathrm{Si} / \mathrm{Al}$ & 3.47 & 1.3 & 0.000 & -0.7 \\
\hline \multirow{3}{*}{$\mathrm{Fe}^{\mathrm{III}} \mathrm{Pd}-\mathrm{Y}^{a}$} & $\mathrm{Fe}-\mathrm{Fe}$ & 3.01 & 2.0 & 0.000 & -9.0 \\
\hline & $\mathrm{Fe}-\mathrm{OZ}$ & 1.97 & 4.8 & 0.004 & +2.3 \\
\hline & $\mathrm{Fe}-\mathrm{Si} / \mathrm{Al}$ & 3.46 & 3.7 & 0.000 & -2.7 \\
\hline \multirow{3}{*}{$\mathrm{PdFe}-\mathrm{Y}$} & $\mathrm{Fe}-\mathrm{Fe}$ & 3.01 & 2.1 & 0.000 & +9.9 \\
\hline & $\mathrm{Fe}-\mathrm{OZ}$ & 1.95 & 2.2 & 0.004 & -9.8 \\
\hline & $\mathrm{Fe}-\mathrm{OZ}$ & 2.11 & 1.5 & 0.000 & -0.4 \\
\hline \multicolumn{6}{|c|}{$295 \mathrm{~K}$ Hydrogen } \\
\hline $\mathrm{Fe}^{11 \mathrm{II}} \mathrm{Pd}-\mathrm{Y}$ & $\mathrm{Fe}-\mathrm{OZ}$ & 1.95 & 2.8 & 0.004 & +4.5 \\
\hline $\mathrm{PdFe}-\mathrm{Y}$ & $\mathrm{Fe}-\mathrm{OZ}$ & 2.06 & 3.2 & 0.006 & -1.6 \\
\hline \multicolumn{6}{|c|}{$423 \mathrm{~K}$ Hydrogen } \\
\hline $\mathrm{Fe}^{\mathrm{II}} \mathrm{Pd}-\mathrm{Y}$ & $\mathrm{Fe}-\mathrm{OZ}$ & 2.04 & 3.6 & 0.006 & -0.8 \\
\hline & $\mathrm{Fe}-\mathrm{Si} / \mathrm{Al}$ & 3.45 & 4.3 & 0.001 & -1.2 \\
\hline $\mathrm{PdFe}-\mathrm{Y}$ & $\mathrm{Fe}-\mathrm{OZ}$ & 2.05 & 4.2 & 0.005 & -1.3 \\
\hline \multicolumn{6}{|c|}{$623 \mathrm{~K}$ Hydrogen } \\
\hline $\mathrm{Fe}-\mathrm{Y}$ & $\mathrm{Fe}-\mathrm{OZ}$ & 2.03 & 4.0 & 0.009 & +0.0 \\
\hline & $\mathrm{Fe}-\mathrm{Si} / \mathrm{Al}$ & 3.46 & 5.7 & 0.003 & -3.6 \\
\hline
\end{tabular}

a This sample was not dehydrated after the second ion exchange $\left(\operatorname{Pd}^{2+}\right)$.

shells are visible). The first shell fit gave an $\mathrm{Fe}-\mathrm{O}$ coordination number of 3.1 as compared to 6.5 of the hexaquo complex and showed a bond contraction from 2.11 to $1.92 \AA$. Bond distances of $\mathrm{Fe}-\mathrm{O}=2.16$ and $2.36 \AA$ were found with $\mathrm{X}$-ray diffraction in $\mathrm{Fe}-\mathrm{Y}$ zeolites dehydrated under vacuum at $673 \mathrm{~K}$ and exposed to 100 Torr of oxygen. ${ }^{35}$ However, the observed bond lengths in our samples are comparable with those of hematite: $\mathrm{Fe}^{3+}-\mathrm{O}$ $=1.945 \AA, \mathrm{Fe}^{2+}-\mathrm{O}=2.116 \AA{ }^{36}$ Thus, we suggest that the bond contraction is a strong indication for the oxidation of $\mathrm{Fe}^{2+}$ to $\mathrm{Fe}^{3+}$ (see also discussion of the corresponding XANES data).

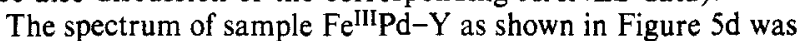
taken after $\mathrm{Fe}(\mathrm{II})$ ion exchange, oxidative dehydration, and subsequent $\mathrm{Pd}$ exchange. Comparison with the $\mathrm{Fe}-\mathrm{Y}$ analogue (Figure $5 \mathrm{c}$ ) reveals a close resemblance to the latter sample. Here, a higher coordination number $N=4.8$ is obtained for the $\mathrm{Fe}-\mathrm{O}$ shell. This sample was not yet dehydrated for a second time after palladium exchange; thus, the additional oxygens have to be interpreted as water coordinated to the anchored iron cations. This results in a slight increase of the bond distance to $1.97 \AA(1.92$ $\AA$ for $\mathrm{Fe}-\mathrm{Y})$. Probably some more iron ions reside in cation positions as indicated by a larger $\mathrm{Fe}-\mathrm{Si}$ coordination number $(N$ = 3.7; Fe-Y, $N=1.3$ ).

The sequence of cation exchange has some influence on the homogeneity of the Fe phase: Sample PdFe-Y, first exchanged with $\mathrm{Pd}^{2+}$, dehydrated, and subsequently exchanged with $\mathrm{Fe}^{2+}$ shows two different oxygen coordination distances after the second dehydration (see Table II).

Reduction with Hydrogen. The EXAFS data of sample Fe-Y after hydrogen reduction at $623 \mathrm{~K}$ (Figure Se) reveal that intrazeolite $\mathrm{Fe}^{3+}$ can be reduced to $\mathrm{Fe}^{2+}$ under simultaneous redispersion of the small amount of $\mathrm{FeO}_{x}$. A longer $\mathrm{Fe}-\mathrm{O}$ bond of $2.03 \AA$ is obtained, and a fit of the outer shell with the $\mathrm{Fe}-\mathrm{Si}$ calculated reference results in Fe-Si: $N=5.7$ and $R=3.46 \AA$ (a fit with an $\mathrm{Fe}-\mathrm{Fe}$ shell was not possible). These values are consistent with a coordination of iron to the six-ring windows of the zeolite framework. A similar re-reduction is observed in samples $\mathrm{Fe}{ }^{I I I} \mathrm{Pd}-\mathrm{Y}$ and $\mathrm{PdFe}-\mathrm{Y}$ when reduced at $423 \mathrm{~K}$. Bond relaxation to $2.04 \AA$ and the appearance of solely $\mathrm{Fe}-\mathrm{Si} / \mathrm{Al}$ in

(35) Pearce, J. R.; Mortier, W. J.; Uytterhoeven, J. B.; Lunsford, J. H. J. Chem. Soc. Faraday Trans. 1 1981, 77, 937.

(36) Blake, R. L.; Hessevick, R. E.; Zoltai, T.; Finger, L. W. Am. Mineral. $1966,51,123$ 

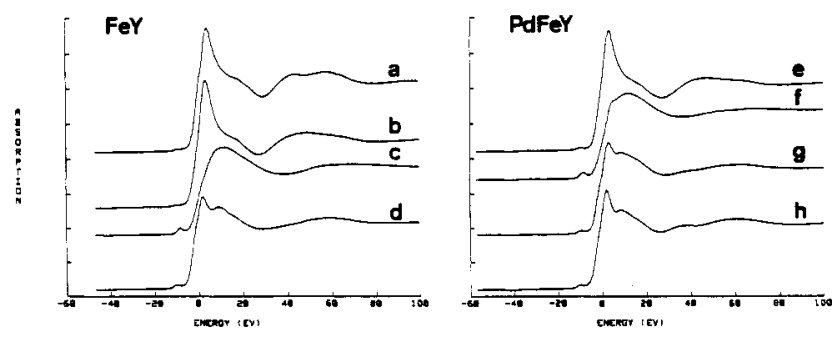

Figure 6. Preedge and XANES region of Fe-edges of sample Fe-Y: (a) $\mathrm{FeSO}_{4}$ precursor, (b) Fe-Y after ion exchange, (c) Fe-Y after dehydration under oxygen at $623 \mathrm{~K}$, and (d) $\mathrm{Fe}-\mathrm{Y}$ after hydrogen reduction at $623 \mathrm{~K}$. Sample PdFe-Y: (e) after ion exchange with $\mathrm{FeSO}_{4}$, (f) after dehydration under oxygen at $623 \mathrm{~K},(\mathrm{~g})$ after hydrogen reduction at room temperature, and (h) $423 \mathrm{~K}$.

the outer shell takes place. Similar results are also obtained with sample $\mathrm{PdFe}-\mathrm{Y}$.

Iron-Absorption Edges ( $X A N E S$ ). The oxidation and reduction processes of the intrazeolite iron ions under different conditions are clearly reflected in the signatures and positions of the respective iron absorption edges. In Figure 6 (left), the normalized edge spectra of the precursor compound $\mathrm{FeSO}_{4}$ (a) are compared with those of sample Fe-Y after ion exchange (b), dehydration at 623 $\mathrm{K}$ in oxygen (c), and hydrogen reduction at $623 \mathrm{~K}$ (d). Almost no change is visible between the precursor and aqueous $\mathrm{Fe}-\mathrm{Y}(6 \mathrm{~b})$. Both samples show very weak $1 \mathrm{~s} \rightarrow 3 \mathrm{~d}$ transitions and a distinctive "white line" as found for a number of divalent, 6-fold oxygen coordinated iron compounds. ${ }^{37}$ The edge features of these samples confirm the above EXAFS results, indicating that neither the oxidation state nor the ligand sphere (symmetry) has changed upon diffusing the iron cation into the zeolite. However, oxygen treatment causes drastic changes in the form of an edge shift of about $2 \mathrm{eV}$ to higher energies (c) and an increase of the preedge feature. A similar edge shift was reported for the oxidation of $\mathrm{Fe}^{2+}$ to $\mathrm{Fe}^{3+}$, and it appears that the change in the preedge is related to a decrease in the $\mathrm{Fe}-\mathrm{O}$ coordination number. ${ }^{37}$ The edge shape itself is similar to that of $\mathrm{Fe}^{\mathrm{III}}$ acac. Changes in the edge shape indicate a different ligand sphere after oxidation/ dehydration as found in the corresponding EXAFS data (Fe-Si, $\mathrm{Fe}-\mathrm{Fe}$, and different oxygen coordination). In Figure 6d, the reduction to a lower oxidation state is apparent by the reverse shift of the absorption edge. Together with the EXAFS data of this sample, it can be interpreted with the coordination of most of the iron ions to the zeolite framework in the form of $\mathrm{Fe}^{2+}$.

The absorption edges of sample PdFe-Y (Figure 6, right) show similar trends: $\mathrm{Fe}^{2+}$ is in an octahedral environment comparable to the precursor $\mathrm{FeSO}_{4}$ after ion exchange (e). Oxidation to $\mathrm{Fe}^{3+}$ occurs after oxygen exposure (f). From $g$ and $h$, it is apparent that hydrogen treatment at room temperature $(\mathrm{g})$ and $423 \mathrm{~K}(\mathrm{~h})$ is already sufficient to reduce $\mathrm{Fe}^{3+}$ to $\mathrm{Fe}^{2+}$.

Potential $\mathrm{Fe}-\mathrm{Pd}$ Interactions. From the analysis of the $\mathrm{Fe}$ EXAFS and XANES data, it can be concluded that the intrazeolite iron ions are always at least partially coordinated to the zeolite framework. Only minor differences in the degree of iron oxide formation could be found between $\mathrm{Fe}-\mathrm{Y}$ and the bimetal-exchanged samples. An Fe-Pd interaction does not occur, since no peak in the Fe EXAFS spectra corresponding to any peak in the palladium EXAFS spectra is observed in the Fourier transforms of the bimetallic samples. If present at all, such interaction should result in a peak of a distance at about $2.6 \AA$, since this is the only overlap of peaks in the spectra of each absorption edge. Compare for example Figure if to Figure $5 f$ for Fe $\mathrm{F}^{\mathrm{lII}} \mathrm{Pd}-\mathrm{Y}$ after $423 \mathrm{~K}$ hydrogen reduction. Fits of the peaks at about $2.6 \AA$ (uncorrected) on either absorption edge were perfect when only a single scatterer pair ( $\mathrm{Pd}-\mathrm{Pd}$ or $\mathrm{Fe}-\mathrm{Si})$ was used. Furthermore, the sample characteristics are very similar to their respective single-metal-exchanged counterparts $(\mathrm{Pd}-\mathrm{Y}$ or $\mathrm{Fe}-\mathrm{Y}$ ). An EXAFS study about $\mathrm{Pd}_{3} \mathrm{Fe}$ alloy formation between $\mathrm{Fe}$ and $\mathrm{Pd}$ was reported of a sample prepared by coimpregnation

(37) Waychunas, G. A.; Apted, M. J.; Brown, G. E. Phys. Chem. Miner. $1983,10,1$.
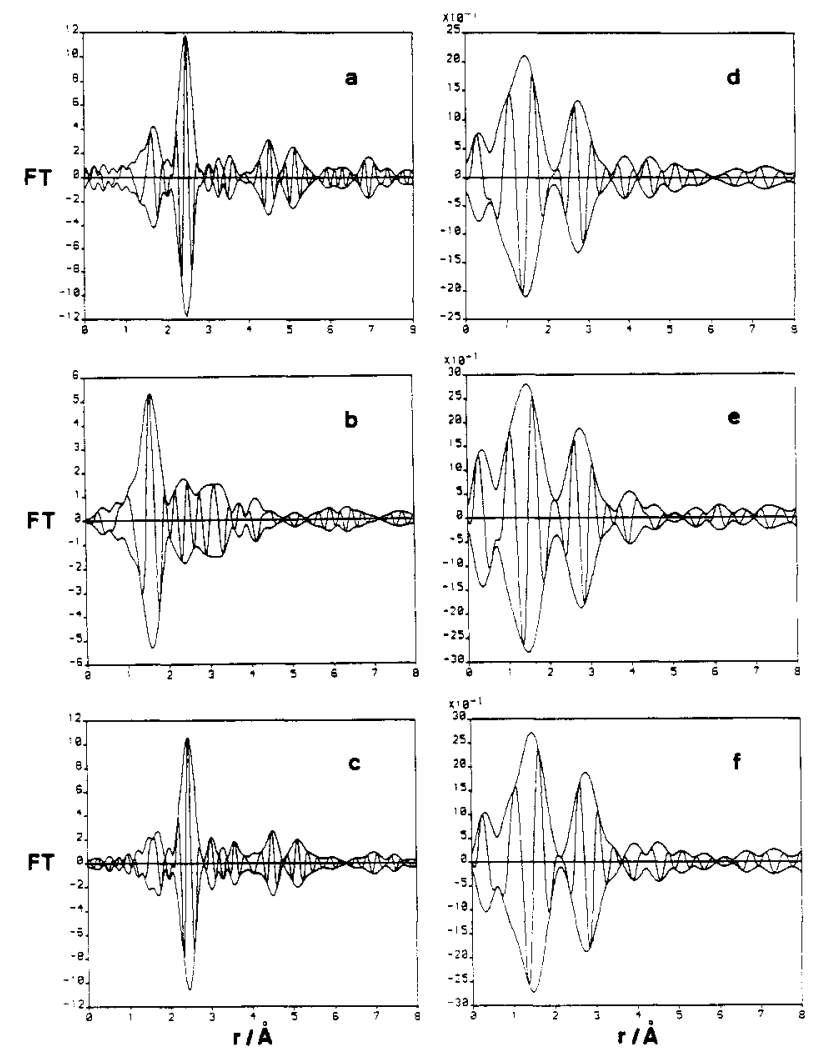

Figure 7. $k^{3}$.Weighted Fourier transforms of sample FePd-Y of the Pd-edges $(a, b, c)$ and Fe-edges $(d, e, f)$ after ion exchange $(a, d)$, after dehydration under oxygen at $623 \mathrm{~K}(\mathrm{~b}, \mathrm{e})$, and after hydrogen reduction at room temperature $(\mathrm{c}, \mathrm{f})$.

of the respective chlorides on an amorphous support and hydrogen reduction. ${ }^{38}$ We can definitively rule out the presence of such a composite in the zeolite since the iron is always in an oxidized form.

Reversed Sequence of $\mathrm{Pd} / \mathrm{Fe}$ Ion Exchange. It is of interest to compare the above results with those obtained when $\mathrm{Fe} / \mathrm{Pd}$ bimetallic zeolites are prepared in the reversed sequence of ion exchange. $\mathrm{Fe}^{2+}$ ions were introduced first into the zeolite framework under anaerobic conditions and washed, and without any intermediate dehydration, palladium tetraammine chloride was added to the dispersion (sample FePd-Y). Immediately upon introduction of the palladium ions, a drastic color change of the zeolite dispersion from light green to black was observed. The sample was filtered and partitions were dehydrated similar to the previously discussed samples under oxygen atmosphere at $623 \mathrm{~K}$ and subsequently reduced under hydrogen atmosphere at room temperature.

$P d$-Edge EXAFS. Figure 7 shows the $k^{3}$-weighted Fourier transforms of EXAFS data of these samples taken at the Pd (3-17 $\left.\AA^{-1}\right)$ and $\mathrm{Fe}\left(3.5-9.5 \AA^{-1}\right)$ absorption edges. Data of sample FePd-Y after ion exchange are depicted in Figure 7a. The formation of fairly large palladium metal particles is obvious, as Pd-Pd scattering can be identified up to the 7 th shell. All Pd-Pd atom pairs have bond distances identical with those of bulk palladium and do not deviate even in the static disorder. This indicates that a large part of the $\mathbf{P d}^{2+}$ ions are reduced to $\mathbf{P d}^{0}$ by the presence of iron(II) ions. Corresponding electron micrographs show Pd particles with diameters greater than $50 \AA$ clustered at the surface of the zeolite crystals. However, the reduction is incomplete indicated by the first-shell $\mathrm{Pd}-\mathrm{O}$ contribution at about $1.8 \AA$ with a coordination number of 2.5 . This number is considerably smaller than $N=6$ for $\mathrm{Pd}^{2+}$ in solution and can be interpreted with the reduction of about $50 \%$ of the total palladium ions present. Fit results including the Pd-Pd outer shells are listed in Table III.

(38) Kuroda, H.; Yokoyama, T.; Kosugi, N.; Ichikawa, M.; Fukushima, T. J. Phys. 1986, C 8,301 . 
TABLE III: Structural Data for Sample FePd-Y As Derived from EXAFS Data

\begin{tabular}{|c|c|c|c|c|}
\hline atom pair & $R / \AA$ & $N$ & $\Delta \sigma^{2} / \AA^{2}$ & $\Delta E / \mathrm{eV}$ \\
\hline \multicolumn{5}{|c|}{ Pd-Edge } \\
\hline $\begin{array}{l}\mathrm{Pd}-\mathrm{O} \\
\text { 1. } \mathrm{Pd}-\mathrm{Pd} \\
\text { 3. } \mathrm{Pd}-\mathrm{Pd} \\
\text { 4. } \mathrm{Pd}-\mathrm{Pd}\end{array}$ & $\begin{array}{l}1.99 \\
2.75 \\
4.76 \\
5.49\end{array}$ & $\begin{array}{l}\text { Hyc } \\
2.5 \\
2.5 \\
5.0 \\
2.8\end{array}$ & $\begin{array}{l}d \\
0.000 \\
0.000 \\
0.001 \\
0.001\end{array}$ & $\begin{array}{l}-1.5 \\
-2.6 \\
-1.2 \\
+0.0\end{array}$ \\
\hline \multicolumn{5}{|c|}{$623 \mathrm{~K}$ Oxygen } \\
\hline $\begin{array}{l}\mathrm{Pd}-\mathrm{O} \\
\text { 1. } \mathrm{Pd}-\mathrm{Pd} \\
\text { 3. } \mathrm{Pd}-\mathrm{Pd} \\
\text { 4. } \mathrm{Pd}-\mathrm{Pd}\end{array}$ & $\begin{array}{l}{ }^{2} \\
1.99 \\
2.74 \\
4.77 \\
5.49\end{array}$ & $\begin{array}{l}\text { Hyd } \\
1.5 \\
2.5 \\
4.0 \\
2.0\end{array}$ & $\begin{array}{l}0.000 \\
0.000 \\
0.000 \\
0.001\end{array}$ & $\begin{array}{l}-2.8 \\
-2.9 \\
-6.0 \\
-4.3\end{array}$ \\
\hline \multicolumn{5}{|c|}{ Fe-Edge } \\
\hline $\begin{array}{l}\mathrm{Fe}-\mathrm{O} \\
\mathrm{Fe}-\mathrm{Fe}\end{array}$ & $\begin{array}{l}1.97^{2} \\
3.06\end{array}$ & $\begin{array}{l}\text { Hyc } \\
3.0 \\
4.7\end{array}$ & $\begin{array}{l}\mathrm{d} \\
0.005 \\
0.002\end{array}$ & $\begin{array}{l}+1.4 \\
-2.1\end{array}$ \\
\hline $\begin{array}{l}\mathrm{Fe}-\mathrm{O} \\
\mathrm{Fe}-\mathrm{Fe}\end{array}$ & $\begin{array}{l}1.95 \\
3.05\end{array}$ & $\begin{array}{l}6 \mathrm{Ox} \\
3.4 \\
7.2\end{array}$ & $\begin{array}{l}0.005 \\
0.002\end{array}$ & $\begin{array}{l}+0.5 \\
-3.8\end{array}$ \\
\hline $\begin{array}{l}\mathrm{Fe}-\mathrm{O} \\
\mathrm{Fe}-\mathrm{Fe}\end{array}$ & $\begin{array}{l}1.98^{2} \\
3.05\end{array}$ & $\begin{array}{l}\text { Hyc } \\
3.4 \\
7.9\end{array}$ & $\begin{array}{l}0.004 \\
0.004\end{array}$ & $\begin{array}{l}+0.0 \\
-3.7\end{array}$ \\
\hline
\end{tabular}

Figure $7 \mathrm{~b}$ shows that heating of this sample up to $623 \mathrm{~K}$ in oxygen atmosphere causes nearly complete redispersion of the metal phase to $\mathrm{Pd}^{2+}$ cations and $/$ or $\mathrm{Pd}^{0}$ atoms. Only about $1 / 10^{1}$ th of the previous Pd-Pd peak is still visible. Bergeret et al. ${ }^{22}$ observed a similar redispersion with $15-\AA$ Pd particles heated in oxygen. Subsequent hydrogen reduction at room temperature results again in agglomeration to larger particles, as shown in Figure 7c. The degree of reduction appears to be higher than after the initial reduction, since only $1.5 \mathrm{Pd}$-oxygen neighbors are found on average.

$F e-E d g e$ EXAFS. The above observations demonstrate a redox reaction between intrazeolite $\mathrm{Fe}^{2+}$ and $\mathrm{Pd}^{2+}$. Analysis of the hydrated sample FePd-Y after ion exchange at the iron absorption edge shows a short bond length of $R=1.97 \AA$ for $\mathrm{Fe}-\mathrm{O}$ (Figure $7 \mathrm{~d})$. This is considerably shorter than that of Fe-Y $(2.11 \AA)$ and is usually only found after dehydrating and oxydizing the iron to $\mathrm{Fe}^{3+}$. Furthermore, the coordination number $N=3$ is very different compared to $N=6$ of the hexaquo complex. Fitting of the outer shell was obtained with a single-shell contribution of $\mathrm{Fe}-\mathrm{Fe}$ with a bond length identical with that of $\mathrm{FeO}(R=3.06$ $\AA)$. All these findings point to a redox reaction between palladium and iron and the simultaneous precipitation of iron oxide. The iron oxide is stable against subsequent treatments: when the sample is heated in oxygen, only a slight increase of the first and second shell is observed (Figure 7e), which are almost unchanged after hydrogen exposure at room temperature (Figure 7f; see Table III).

The oxidation to $\mathrm{Fe}^{3+}$ is also visible in the absorption edge spectra (Figure 8). It can be seen that the absorption edge of $\mathrm{Fe}-\mathrm{Y}$ (a) is shifted to higher energies as soon as palladium is introduced to the aqueous dispersion to give sample FePd-Y (b). The new edge shape is comparable to that of $\mathrm{Fe}-\mathrm{Y}$ after oxidation at $623 \mathrm{~K}$ (Figure $6 \mathrm{c}$ ) where a substantial contribution of iron oxide particles was found. The edge features do not change when treating FePd-Y with oxygen or hydrogen $(c, d)$. The chemistry of iron and palladium in aqueous intrazeolite "solutions" therefore favors a redox reaction under formation of an iron oxide phase and palladium particles.

\section{Conclusion}

This study addresses the question of whether a less reducible transition metal has an influence on the reduction and agglomeration behavior of a noble intrazeolite metal, i.e., palladium. A

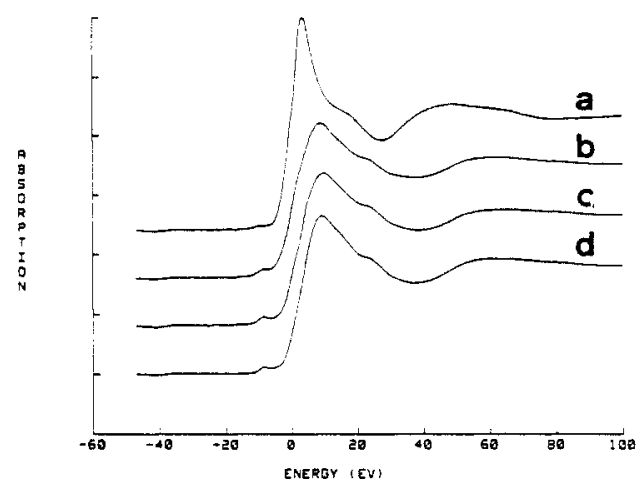

Figure 8. (a) Absorption-edge features of sample $\mathrm{Fe}-\mathrm{Y}$ after ion exchange, (b) absorption edge of sample FePd-Y after ion exchange, (c) $\mathrm{FePd}-\mathrm{Y}$ after dehydration under oxygen at $623 \mathrm{~K}$, and (d) FePd-Y after hydrogen reduction at room temperature.

chemical anchoring mechanism was proposed by Sachtler et al. to explain for their observation that the addition of iron to Ptexchanged zeolites resulted in an enhanced dispersion as concluded from X-ray diffraction and adsorption measurements. ${ }^{15}$ This effect was only detected at an $\mathrm{Fe} / \mathrm{Pt}$ ratio greater than 0.5 and at high reduction temperatures of $923 \mathrm{~K}$ under hydrogen. Since X-ray powder diffraction is not very sensitive for changes in particle size smaller than $50 \AA$ or any $M-M^{\prime}$ interaction, other techniques such as EXAFS are expected to give more insight as to the structure and confinement of metal particles. A related EXAFS study of the $\mathrm{Rh}$-edge of $\mathrm{Rh} / \mathrm{CrNa}-\mathrm{Y}$ zeolite showed a decrease in the $\mathrm{Rh}-\mathrm{Rh}$ peak under high-temperature reduction and was explained by the presence of an additional $\mathrm{Rh}-\mathrm{Cr}$ contribution. ${ }^{16}$ However, a subsequent Pt-edge EXAFS study of $\mathrm{Ca}, \mathrm{La}$, or Fe coexchanged $\mathrm{Pt}-\mathrm{Y}$ zeolites by Sachtler et al. did not confirm interactions between $\mathrm{Fe}^{2+}$ ions and the reduced Pt phase. ${ }^{39}$

In a recent EXAFS study on Co/Pd-exchanged zeolites where spectra were taken at both absorption edges, ${ }^{19}$ we could show that the addition of cobalt increased the reducibility of the palladium phase. Similar trends were reported when $\mathrm{Ni}, \mathrm{Cr}$, or $\mathrm{Mn}$ ions were added to $\mathrm{Pt}$ in zeolite $\mathrm{Y} .{ }^{40}$ In the $\mathrm{Co} / \mathrm{Pd}$ system, palladium particles formed at room temperature were larger than in the parent $\mathrm{Pd}-\mathrm{Y}$ zeolite (EXAFS results are included in Table I). However, reduction at higher temperatures resulted in higher dispersion as compared to $\mathrm{Pd}-\mathrm{Y}$ under similar conditions. This effect could not be associated with a chemical anchoring process, since the cobalt absorption edge spectra did not differ from those of the $\mathrm{Co}_{0} \mathrm{Y}$ sample. It was concluded that the reduced particle size is associated with a change in the cation distribution: $\mathrm{Co}$ cations are preferrentially coordinated in the sodalite cages and force the palladium cations into the supercages. The latter are thus more accessible to the reducing atmosphere and form $\mathbf{P d}$ clusters of about supercage dimensions at low temperatures. The resulting clusters are locked into the zeolite cages and are less mobile at higher reduction temperatures; thus, they do not agglomerate further (compare samples Pd-Y and CoPd-Y at 623 $\mathrm{K}$ hydrogen reduction in Table $\mathrm{I}$ ).

The present study shows that the situation is different in the $\mathrm{Fe} / \mathrm{Pd}-\mathrm{Y}$ systems. The enhanced reducibility of palladium upon addition of a second metal is still noticeable at room temperature but to a much smaller extent (about 55-60\% of all Pd ions are reduced compared to $35 \%$ in $\mathrm{Pd}-\mathrm{Y}$ ). High-temperature reduction shows only a slightly higher dispersion when iron is present, but the effect is much less drastic compared to the cobalt/Palladium system. Thus, iron does not influence the Pd particle growth at the microscopic scale, and no chemical interaction between the two intrazeolite metals is detected by analysis of both the Pd and Fe X-ray absorption edge.

A possible explanation for the difference between iron and cobalt systems may be based on the formation of iron oxide clusters

(39) Tzou, M. S.; Teo, B. K.; Sachtler, W. M. H. J. Catal. 1988, 113, 220.

(40) Tzou, M. S.; Jiang, H. J.; Sachtler, W. M. H. React. Kinet. Catal. Lett. 1987, 35, 207. 
in the iron-containing samples. In all samples, some oxide formation was detected by the appearance of an Fe-Fe shell at 3.01 $\AA$. The particle size of these clusters is estimated to be at least $6 \AA$; thus, it is very likely that they are located in the supercages rather than sodalite units. This could eliminate the site-directing effect of the second transition metal on the position of the Pd phases, and the effect on the reducibility is expected to be minimal.

This analysis shows that the interplay of metals in bimetallic zeolite catalyst is not easily predictable and is strongly dependent on the chemistry of each constituent. EXAFS is a valuable technique for structure determination of these complex systems by probing the ligand spheres of each component separately. On the basis of subtle changes in zeolite oxygen coordination of the metal, it is demonstrated that EXAFS is also very sensitive for the analysis of intrazeolite reduction degrees.

Acknowledgment. Acknowledgment is made to the donors of the Petroleum Research Fund, administered by the American Chemical Society, and to the Sandia-University Research Program (DOE), for partial support of this research. The operational funds for NSLS beamline X-11A are supported by DOE Grant DE-AS0580ER10742.

Registry No. Pd, 7440-05-3; Fe, 7439-89-6; Co, 7440-48-4.

\title{
Electrophoretic Light Scattering of Surfactant Micelle Colloids
}

\author{
Toyoko Imae,* \\ Department of Chemistry, Faculty of Science, Nagoya University, Chikusa, Nagoya 464, Japan
}

William Otani, and Koichi Oka

Otsuka Electronics Company, Ltd., Hirakata, Osaka 573, Japan (Received: May 8, 1989; In Final Form: June 27, 1989)

\begin{abstract}
Aqueous micellar solutions were investigated by the electrophoretic light scattering method. The electrophoretic mobilities of $(2-4) \times 10^{-4} \mathrm{~cm}^{2} \mathrm{~V}^{-1} \mathrm{~s}^{-1}$ were obtained for charged micelles of tetradecyl- and hexadecyltrimethylammonium salicylates $\left(\mathrm{C}_{14}\right.$ TASal, $\mathrm{C}_{16}$ TASal $)$ and partly protonated tetradecyl- and oleyldimethylamine oxides $\left(\mathrm{C}_{14} \mathrm{DAO}\right.$ and ODAO).
\end{abstract}

\section{Introduction}

Electrophoretic light scattering is a beneficial method in which the electrophoretic mobility and the mutual diffusion coefficient can be measured simultaneously. Since the initial development of theory and experimental procedures by Ware and Flygare, ${ }^{1}$ the technique has been applied to solutions of biomolecules, biomicelles, and polyelectrolytes and to suspensions of polymer latex particles and mineral colloidal particles. ${ }^{1-6}$ However, applications to surfactant micelle colloidal systems have not been achieved as yet.

In the present paper, electrophoretic light scattering measurements were carried out for aqueous micellar solutions of $\mathrm{C}_{14}$ TASal, $\mathrm{C}_{16}$ TASal and partly protonated $\mathrm{C}_{14} \mathrm{DAO}$ and ODAO. The electrophoretic mobilities of charged micelles are obtained together with their mutual diffusion coefficients.

\section{Experimental Section}

Samples of $\mathrm{C}_{14}$ TASal and $\mathrm{C}_{16}$ TASal were prepared by reacting the corresponding alkyltrimethylammonium halides with sodium salicylate in water. The preparation will be described in detail in a subsequent paper. ${ }^{7}$ Samples of $\mathrm{C}_{14} \mathrm{DAO}$ and ODAO are the same as those previously prepared and used. ${ }^{8,9} \quad \mathrm{C}_{14} \mathrm{DAO}$ and

(1) Ware, B. R.; Flygare, W. H. Chem. Phys. Lett. 1971, 12, 81; J. Colloid Interface Sci. 1972, 39, 670 . 74.

(2) Urgiris, E. E. Opt. Commun. 1972, 6, 55; Rev. Sci. Instrum. 1974, 45,

(3) Yoshimura, T.; Kikkawa, A.; Suzuki, N. Jpn. J. Appl. Phys. 1972, 11, 1979; Jpn. J. Appl. Phys. 1975, 14, 1853; Opt. Commun. 1975, 15, 277. (4) Ware, B. R.; Haas, D. D. Electrophoretic Light Scattering. In Fast Methods in Physical Biochemistry and All Biology; Shâafi, R. I., Fernandeg,

S. M., Eds.: Elsevier: New York, 1983; Chapter 8.

(5) Dalgleish, D. G. J. Dairy Res. 1984, 51, 425. Holt, C.; Dalgleish, D. G. J. Colloids Interface Sci. 1986, 114. 513.

(6) Dalbiez, J. P.; Tabti, K.; Darian, P. J.; Drifford, M. Rev. Phys. Appl. 1987, 22, 1013.

(7) Imae, T.; Hashimoto, K.; Ikeda, S. Colloid Polym. Sci., in press. 67.

(8) Abe, A.; Imae, T.; Shibuya, A.; Ikeda, S. Surf. Sci. Technol. 1988, 4,

(9) Imae, T.; Ikeda, S. J. Colloid Interface Sci. 1984, 98, 363; Colloid Polym. Sci. 1985, 263, 756
ODAO are weak bases and are partly protonated in the presence of $\mathrm{HCl}$.

The electrophoretic mobility and the mutual diffusion coefficient were measured at $25^{\circ} \mathrm{C}$ on Otsuka Electronics electrophoretic light scattering spectrophotometer, ELS-800. He-Ne laser light at $632.8 \mathrm{~nm}$ was used. The electrophoretic rectangular cell of $2 \times 10 \times 17 \mathrm{~mm}$ is separated by cellulose semipermeable membranes from the electrode chambers, which hold the Pt electrodes coated with Pt-black.

The electric field, which is perpendicular to the incident radiation, is applied in 1-s pulses that are reversed on each successive application. The sign of the electrophoretic mobility was determined by modulating the frequency of the reference light. The autocorrelation function of the dynamic light scattering was analyzed by a fast Fourier transform routine.

\section{Results}

When the electric field, $E$, is applied to aqueous solutions of charged particles, the particles are moved by an electrophoretic drift velocity of $v$. Then, the electrophoretic mobility, $U$, is described as the velocity per unit electric field, that is

$$
U=v / E
$$

On the basis of the photon correlation method by the heterodyne mixing mode, the first-order autocorrelation power spectrum, $F_{1}(\mu, \omega)$, of the light scattered from the moving particles in solutions under the external electric field applied perpendicularly to the incident radiation is written by

$$
F_{1}(\mu, \omega)=\frac{\langle N\rangle}{\pi} \frac{\mu^{2} D}{(\omega+\mu \cdot v)^{2}+\left(\mu^{2} D\right)^{2}}
$$

and

$$
\mu \cdot \mathbf{v}=\mu v \cos (\theta / 2)
$$

where $\mu$ and $\mu$ are the scattering vector and its magnitude, respectively; $\omega$ is the angular frequency; $\langle N\rangle$ is the average number of scatterers; $D$ is the mutual diffusion coefficient; and $\theta$ is a scattering angle. The power spectrum exhibits a Lorentzian peak 